\title{
LA DIMENSIÓN DE LA SOBERANÍA JURÍDICA EN LA ACTUAL SOCIEDAD INTERNACIONAL GLOBALIZADA
}

\author{
Marcio Morena Pinto ${ }^{1}$
}

\section{Resumen}

El presente artículo pretende percibir y valorar el alcance jurídico de la soberanía desde la perspectiva de su proyección internacional, con vistas a constatar que, a pesar de las modificaciones introducidas por la globalización, especialmente en su actual fase y que, en cierta medida, modificaron la forma de su ejercicio para corresponder a las necesidades de integración demandadas por un nuevo contexto social, económico y político, no se puede afirmar que los factores y fuerzas que pasaron a cuestionar el protagonismo de los Estados en la sociedad internacional hayan adquirido el impulso necesario para desarraigarla, o alterar su condición jurídica de elemento intrínseco a la existencia propia del Estado. En lo que concierne a la metodología aplicada, se hizo uso del método analítico-descriptivo, utilizándose de la investigación bibliográfica para su construcción y fundamentación teórica.

Palabras-clave: Estado; Globalización; Nacionalismo; Soberanía: Sociedad internacional.

\section{INTRODUCCIÓN}

El Estado, como un producto resultante del proceso civilizatorio de la humanidad, constituyó la personificación de la inherente tendencia del ser humano a la organización. En otras palabras, representó la síntesis perfecta de la evolución político-social hacia el alcance de una convivencia más armónica, bajo una normativa jurídica reguladora (SALVETTI NETTO, 1977, p. 42).

El afianzamiento de ese proceso se dio entre los siglos XV y XVI, con la formación del Estado moderno y la concomitante creación del concepto de soberanía, destacándose, desde luego, la estrecha vinculación existente entre ambos. De ahí que Dallari (2011, p. 78) haya afirmado que el Estado constituyó una forma de organización política que se concretó con la afirmación de un poder soberano, reconocido como el más alto de todos dentro de una precisa delimitación territorial.

De acuerdo con Duverger (1970, p. 54), en el contexto de disputa entre Iglesia, Estado y comunidad que caracterizó en fin de la Edad Media y el inicio de la Edad Moderna, la soberanía ofreció una vía alternativa de 
concebir la legitimidad de las reclamaciones de poder cuando las formas de autoridad hace mucho establecidas dejaron de ser dadas por descontado.

Por esta razón, la idea de soberanía proveyó un vínculo renovado entre el poder político y el ejercicio del gobierno. En este sentido es que se puede afirmar que la soberanía fue ingeniada para dar una respuesta al viejo problema de la naturaleza del poder político. La "persona artificial" del Estado, estructurada por leyes e instituciones con una vida y una estabilidad propias, pasó a ser vista como el sujeto legítimo para ser el depositario de la soberanía (HELD, 1997, p. 61).

Juan Bodino fue uno de los primeros teóricos políticos a probar conceptuar la soberanía, ya en siglo XVI, definiéndola como un poder único, perpetuo, absoluto e indivisible que debe imponer el orden al Estado, y que no puede ser limitado en su ejercicio, ni en responsabilidad, ni en el tiempo. De acuerdo con el pensador francés, al que ostentase la soberanía, cabría el poder ilimitado e indivisible de hacer las leyes sin estar sujeto a su cumplimiento, reflejándose claramente su inclinación hacia la defensa del absolutismo monárquico (BODINO, 1997, p. 72).

Desde ese momento, la soberanía pasó a ser vista como la característica definitoria o constitutiva del poder del Estado, siempre que este poder fuera atribuido a uno en virtud del cargo y no de su persona. Así que un gobernante solo podría ejercer su poder gracias a la posesión de la soberanía, considerada como un don temporal y no como un atributo especial a él otorgado. Por lo tanto, ya poco importaba quién fuera el hombre que poseyera en concreto la soberanía, desde que fuera transitoria y estuviera encarnada en la persona artificial del Estado.

Al no confundir la persona del rey con la del Estado, Bodino inauguró definitivamente la concepción de Estado moderno. A partir de entonces, pasó a ser visto como una unidad política, un cuerpo artificial indivisible y laicizado, a quien se atribuye el derecho general de imponer leyes a todos los ciudadanos, independientemente de su consentimiento individual.

\section{LA TRIANGULAR DIMENSIÓN DE LA SOBERANIA Y SU CONCEPCIÓN JURÍDICA}

Al tratar del tema de la soberanía, es importante tener clara conciencia de que su comprensión no es fácilmente alcanzada con un par de definiciones, pues hay en esta materia contradicciones y ambigüedades, como bien observa Rosenau (1995, p. 101). Por consiguiente, cualquier investigación que se proponga sobre esta temática, acaba sobrepasando el universo estrictamente jurídico.

El análisis de la soberanía debe partir de un triangulo relacional que gira en torno al ámbito social, jurídico y político, siendo la conjunción de estos elementos lo que la torna un poder peculiar del Estado, como señala Reale (2002, p. 139). Con todo, a parte de su evidente importancia histórica, lo que realmente debe ser destacado en el presente estudio es su doble e irreductible dimensión político-jurídica. 
Al hilo de lo afirmado, la idea de soberanía política gira en torno a una totalidad de factores que integran la relación de poder entre gobierno y sociedad, bien como a los órganos institucionalizados de gestión de ese poder, articulándose todo un aparato administrativo para su ejercicio, como afirman Aguilera de Prat y Vilanova (1987, p. 224-225). La soberanía jurídica, a su vez, se traduce en el ejercicio de competencias privativas del Estado, o sea, en su capacidad exclusiva de definir sobre la atributividad de las normas y la eficacia del derecho en su territorio (KAPLAN, KATZENBACH, 1964, p. 48).

La soberanía es ejercida sobre los individuos en cuanto unidad elemental del Estado, no importando que actúen aisladamente o en conjunto. Además, los ciudadanos del Estado están siempre sujetos a su poder soberano, incluso, más allá de los límites territoriales. Por lo tanto, la soberanía es ejercida en dos dominios básicos: uno interno, de caracterización institucional, y otro externo, de proyección en el escenario internacional.

Al tratar de los aspectos interno y externo de la soberanía, explica Mello (1999, p. 17) que:

O primeiro se manifesta nos diferentes poderes do Estado: no Legislativo, Executivo e Judiciário. Ele é a consagração do direito de autodeterminação, isto é, o direito do Estado de ter o Governo e as leis que bem entender sem sofrer interferência estrangeira. $\mathrm{O}$ aspecto externo é o direito à independência que se manifesta no: a) direito de convenção; b) direito à igualdade jurídica; c) direito de legação; d) direito ao respeito mútuo"

El núcleo de los poderes inherentes al ejercicio de la soberanía externa está, sin duda, constituido por aquellos relativos a la defensa y a la exigencia del respeto efectivo de sus tres elementos esenciales: total integridad territorial; existencia pacífica de su población; y plena independencia de decisión política del gobierno para proteger y realizar los intereses que considere propios con total libertad.

En lo que atañe a las características de la soberanía externa, existe un consenso entre los juristas sobre las siguientes: unicidad, indivisibilidad, imprescriptibilidad e inalienabilidad. En lo que atañe a la unicidad, la soberanía es una porque no es posible la convivencia simultánea de dos poderes soberanos sobre un mismo territorio ${ }^{2}$, razón también por la cual tampoco puede ser divisible, aunque internamente sea posible la división de su ejercicio por medio de la distribución de funciones. Es inalienable, pues no se puede transferir ni enajenar bajo ningún título a ninguna persona o grupo de personas ${ }^{3}$; y, por fin, es imprescriptible porque no tiene, en principio, un plazo de duración.

Al dedicarse al análisis de la soberanía, Pastor Ridruejo (2013, p. 283-284) pone de relieve los siguientes puntos: a) en el plano jurídico, la soberanía no es un poder ilimitado del Estado; b) en el plano de los hechos, la soberanía estatal cobra frecuentemente perfiles políticos, pero tampoco, desde esta perspectiva, es un poder ilimitado; c) jurídicamente, la soberanía implica la igualdad de los Estados; d) también en el prisma jurídico, la soberanía comporta la independencia de los Estados y el deber de no intervención; e) el principio de la soberanía

\footnotetext{
${ }^{2}$ En este sentido, observa Heller (1995, p. 214) que es "imposible aceptar que sobre un mismo territorio existan dos unidades decisorias supremas".

${ }^{3}$ Como señaló Paupério (1997, p. 17), la renuncia o la pérdida de la soberanía por un pueblo, una nación, o por el Estado, equivale vol.09, nº 04, Rio de Janeiro, 2016.pp.2489-2506 2491
} 
sigue teniendo carácter constitucional en el Derecho Internacional los días de hoy; y f) la soberanía del Estado tiene carácter funcional y se traduce en la posesión y ejercicio de una serie de competencias.

Más recientemente se tiene entendido que la soberanía, en sus dos formas de existencia, es un poder originario, exclusivo, incondicionado y coactivo. Es un poder originario porque no depende de otros poderes para explicar su existencia, naciendo con el propio Estado como un atributo inseparable. La exclusividad de la soberanía se da porque solamente el Estado la posee. Su incondicionalidad se asienta en la inexistencia de límites internos, a la excepción de los impuestos por el propio Estado. Y, por ende, es coactivo porque el Estado no solo ordena, sino que dispone de medios para hacer cumplir sus órdenes coactivamente (DALLARI, 2011, p. 87-88).

Desde una perspectiva jurídica externa, la soberanía se materializa en el conjunto de poderes supremos que un Estado cualquiera pueda ostentar y ejercer en el marco del ordenamiento jurídico internacional, aunque, de hecho, no los demuestre en la práctica para que pueda ser considerado soberano (MENÉNDEZ, 2005, p. 105). Por consiguiente, la soberanía está condicionada a un reconocimiento de la sociedad internacional de Estados. Según reflexiona Carrillo Salcedo (1976, p. 83):

[...] la soberanía se nos muestra como un principio constitucional del Derecho Internacional, símbolo del hecho de que este último opera sobre la base de coordinación entre los Estados y no de subordinación entre los mismos, y su esencia consiste en el derecho a ejercer las funciones de Estado en un plano de independencia e igualdad respecto de otros Estados.

En otras palabras, a pesar del Estado ser y existir como tal, con independencia del ordenamiento jurídico internacional, su soberanía solo se proyectará en el dominio externo cuando los demás Estados de la comunidad internacional le otorguen significación jurídica, es decir, constaten la existencia de una sociedad humana políticamente organizada sobre un determinado territorio independiente, considerándolo como miembro de esa comunidad, y demostrando la voluntad de con él construir relaciones jurídicas.

En siendo la soberanía una institución, ella también sólo existe en virtud de ciertos acuerdos y expectativas intersubjetivos, pues "no hay soberanía si no hay otro". Se trata de un reconocimiento mutuo de los derechos de cada uno a ejercer la autoridad política de forma exclusiva dentro de sus límites territoriales. Si los Estados dejaran de actuar según esas normas, sus identidades como "soberanos" desaparecerían (WENDT, 1992, p. 412-413).

En este mismo orden de ideas, Biersteker y Weber (1996, p. 3-11) subrayan que, en lugar de asumir simplemente que todos los Estados son soberanos, se debe prestar atención a las formas como cada uno negocia constantemente su soberanía, la define y la reproduce a través de sus relaciones. Eso porque el Estado y la soberanía se constituyen mutuamente en el fluir de las relaciones de la comunidad política doméstica, en su interior y hacia su exterior. 


\section{LA INCIDENCIA DE LA GLOBALIZACIÓN EN LAS RELACIONES INTERNACIONALES EN EL PASAJE DEL SIGLO XX AL XXI}

Tras el término de la Segunda Guerra mundial, el capitalismo ingresó en una nueva fase de desarrollo basada en una dinámica productiva con sofisticada tecnología, casi obligando al mundo a una interdependencia recíproca, lo que ocurrió por medio del establecimiento de organizaciones internacionales y regionales que propiciaron grande transformaciones en el ámbito de las relaciones internacionales.

A esos factores se sumaron dos acontecimientos históricos que enmarcaron el fin definitivo de la bipolaridad que regía las relaciones internacionales hasta entonces: el término de la Guerra Fría y la caída del muro de Berlín. Desde ese momento, empezó a surgir una nueva configuración de la sociedad internacional motivada por el incremento de la globalización, que se consolidó efectivamente en el pasaje del siglo XX al XXI

Como destaca Friedman, si hasta la mitad del siglo XX era posible distinguir claramente un sistema caracterizado por la yuxtaposición de Estados y bajo el cual las relaciones internacionales se configuraban de forma lineal, con algunas ramificaciones que nacían y morían en los grandes Estados (Cold War System) -, a partir del final del siglo XX se perpetúa un sistema representado por el crecimiento de una interdependencia entre los Estados, y que reflejó un esquema mucho más complejo, por medio del cual las relaciones se estructuran formando un tejido de hilos cruzados que parten y terminan en muchos puntos (Globalization system).

Esa mayor aproximación entre Estados se justificó, por una parte, en la necesidad de consolidación de una política de mantenimiento de la paz en el mundo, y, por otra parte, en la creciente necesidad de una mayor integración económica para reestructurar la economía en aquellos momentos, principalmente la europea y de los Estados Unidos, lo que dio inicio a una nueva fase del proceso de globalización.

Esa nueva etapa evolutiva de la globalización produjo un "acortamiento" de las distancias y cierta "flexibilización" de las rígidas fronteras territoriales que por muchos siglos habían servido solamente para delimitar la exclusividad política y la plena autonomía sobre un conjunto de aspectos relacionados con la gestión, la defensa y la conducción de la sociedad en un territorio determinado, haciendo a los Estados repensar la forma de ejercicio de sus soberanías en ese nuevo contexto de cooperación en los campos político, económico y, incluso, jurídico (aunque en menor escala y más a largo plazo).

En este sentido, señala Kehoane (2002, p. 2) que la globalización abrió espacio a nuevas formas de gestión de carácter internacional (o transnacional), resultantes de la referida integración económica de la sociedad internacional. Con ella, la cooperación e interdependencia entre los Estados se tornaron primordiales en los campos económico y estratégico.

\footnotetext{
${ }^{4}$ Merece la pena señalar que la globalización no es un fenómeno nuevo, sino que el resultado de un proceso milenario que se ha visto acelerado en su última fase, que es la que se está viviendo desde fines del siglo XX (TRUYOL Y SERRA, 2002, p. 33). vol.09, no. 04, Rio de Janeiro, 2016. pp. 2489-2506 
La globalización significó en su marco referencial que la humanidad había dejado para atrás la época de la política internacional caracterizada por la dominación de los Estados nacionales que monopolizaban el escenario internacional, ingresando en una nueva época en que los actores estatales deberían compartir escenario y poderes globales con organizaciones internacionales, empresas, movimientos sociales y políticos transnacionales.

En este contexto, Rosenau (1990, p. 56) afirmó que la estructura monocéntrica de poder de los Estados nacionales rivales tendría sido sustituida por un reparto de poder policéntrico, que haría que una gran pluralidad de actores transnacionales y nacionales-estatales compitiesen o cooperasen entre sí.

Parece no existir dudas al respecto de que la globalización, entendida como un fenómeno progresivo y continuo, que promovió un impacto significativo en la sociedad internacional de la posguerra, produciendo un ambiente económico que modificó las condiciones de ejercicio de la autoridad política y acentuó la tendencia de incorporación de actores no-gubernamentales a las relaciones internacionales, señalando a los Estados la necesidad de cambiar la agenda política internacional.

De esta manera, hay que admitir que la forma de ejercicio de la soberanía estatal fue, en cierta medida, alterada, para que pudiera corresponder a las necesidades de integración demandadas por este nuevo contexto de cooperación. No obstante, cabe señalar de antemano que la polémica surgida en torno al debilitamiento de la soberanía estatal parece notoriamente desmesurada.

En este sentido, subraya Polin (1996, p. 12) que jamás un Estado, por más poderoso que fuera, logró sustraerse integralmente a sus condicionamientos de naturaleza jurídica o de orden fáctica, pues la idea de una soberanía sin límites nunca existió, mucho menos tendrá lugar en los días actuales, sobre todo, en razón de las transformaciones históricas por las cuales los Estados han pasado.

A pesar de no existir ninguna interpretación concreta de la globalización que haya alcanzado la condición de ortodoxia en los círculos académicos, como bien constataron Held y McGrew (2003, p. 14), parece oportuno, en el presente contexto de análisis, intentar buscar un formulación que explique mínimamente este fenómeno.

Keohane (2002, p. 2), por ejemplo, ve la globalización como un grupo de procesos que incluye una transformación en la organización espacial de las relaciones sociales y en las transacciones que genera flujos y redes transcontinentales, creando una mayor cooperación e interdependencia entre los Estados bajo la óptica económica, pero también estratégica. Para Stiglitz (2003, p. 34), la globalización es:

[...] la integración más estrecha de los países y de los pueblos del mundo, producida por la enorme reducción de los costes de transporte y comunicación, y el desmantelamiento de las barreras artificiales a los flujos de bienes, servicios, capitales, conocimientos y (en menor grado) personas a través de fronteras.

La globalización significó en su marco referencial que la humanidad ha dejado para tras una época en que la política internacional se caracterizaba por la dominación de Estados nacionales que monopolizaban el escenario internacional. La estructura monocéntrica de poder de los Estados nacionales rivales ha sido sustituida 
por un reparto de poder policéntrico, que hizo que una gran pluralidad de actores transnacionales y nacionalesestatales compitan o cooperen entre sí (ROSENAU, 1990, p. 56).

Es innegable que el desarrollo de la globalización promovió un impacto en la sociedad internacional de la posguerra, produciendo un ambiente económico que modificó las condiciones de ejercicio de la autoridad política y acentuó la tendencia de incorporación de actores no-gubernamentales a las relaciones internacionales, señalando a los Estados la necesidad de cambiar la agenda política internacional.

Como analiza García Segura (1998, p. 324-225), la globalización es un fenómeno de la sociedad contemporánea integrado por un conjunto de procesos interrelacionados que se caracterizan por varios factores: tendencia a extenderse al ámbito planetario; estabilidad en el tiempo; carácter predominantemente, pero no exclusivamente, económico; carácter integrador y socializador, creando un todo que es resultado de múltiples procesos interdependientes que siguen una lógica transnacional hegemónica o de penetración que conlleva una tendencia homogeneizadora; actores transnacionales que limitan cada vez más las capacidades decisorias y reguladoras de los Estados. Asimismo, es un fenómeno en curso, inacabado, y que provoca reacciones contradictorias.

Goldthorpe (2002, p. 1-2) vislumbra la globalización bajo dos esferas: una stricto sensu, que la representa como un fenómeno principalmente económico ${ }^{5}$, y otra lato sensu, que la considera como un fenómeno pluridimensional. Así que, stricto sensu, la globalización "is a process whereby economic activity of all kinds is increasingly organized and conducted in ways that cut across politically defined national or regional boundaries". Al paso que, lato sensu, la globalización significaría un proceso por medio del cual aparecen nuevas formas de gobierno de carácter internacional o transnacional, dándole apoyo a la idea de un nuevo orden político mundial, además del económico.

Enfatizando un lado más social de la globalización, Giddens (1991, p. 70) subraya que, gracias a ella, hubo una intensificación sin precedentes de las relaciones que interconectan las personas y localidades alrededor del mundo, de tal manera que hechos lejanos pasaron a modelar eventos locales y son, a la vez, por ellos también modelados.

La globalización, según menciona Held (1997, p. 42), ha denotado la expansión y la profundización de las relaciones sociales e institucionales a través del espacio y del tiempo, de forma tal que, por un lado, las actividades cotidianas resultan cada vez más influidas por los hechos y acontecimientos que tienen lugar en distintas partes del globo y, por el otro, las prácticas y decisiones de los grupos y comunidades locales acaban por tener importantes repercusiones globales. En conclusión, como subraya Hobsbawm (1995, p. 24), con la globalización el mundo se ha convertido en una única unidad operativa. 
De todos los cambios significativos ocurridos en el período referido, hay que señalar la irrupción de grupos económicos transnacionales (cuyo poder llega, a veces, a ser superior al de muchos Estados); el predominio del modelo neoliberal; la proliferación de los procesos de regionalización; la revolución científica y técnica (principalmente correlacionada al aparecimiento de las redes avanzadas de interconexión); y el surgimiento de nuevas amenazas, más inciertas, difusas y cambiantes, como es el caso de los grupos terroristas (ARENAL, 1993).

Con base a esos cambios, la actual sociedad internacional pasó a ser calificada como heterogénea, compleja, interdependiente y ordenada, además de anárquica, teniendo como elementos constitutivos más importantes: la existencia de diversos actores internacionales; la búsqueda de objetivos múltiples (y, a veces, contradictorios); la aparición de relaciones heterogéneas; el elevado grado de interdependencia que presentan los ámbitos tecnológico y económico; la complejidad que resulta de todos estos factores; y, por ende, la especial relación en la que conviven anarquía y orden en una sociedad en la que, remarca la autora, abundan tanto el conflicto como la cooperación (BARBÉ, 2007, p. 137-138).

Al analizar el tema, Arenal (2001) subraya especialmente la idea de transformación de la sociedad internacional actual, plasmándola en seis dinámicas básicas de cambio: la mundialización y la universalización; la interdependencia de los sujetos internacionales; el auge alcanzado por la globalización; la gran heterogeneidad; la estatalización como herramienta de mantenimiento de las estructuras nacionales e internacionales; y la humanización, confluyendo todos para convertirla en una realidad universal y planetaria, heterogénea y compleja, interdependiente y global, políticamente no integrada e insuficientemente regulada, desequilibrada y desigual.

Por consiguiente, lo que se puede vislumbrar en la sociedad internacional contemporánea son básicamente tres estructuras bien definidas y que se interpenetran mutuamente, a pesar de poseer rasgos estructurales y dinámicas diferentes: una sociedad de Estados; una sociedad o sistema transnacional; y una sociedad humana.

En cualquier caso, como destacan Van Staden y Vollaard (2004), la primera estructura es la que sigue predominando, no restando dudas de que el Estado, gracias a su poder político y militar, sigue siendo el pilar básico de la sociedad internacional.

\footnotetext{
${ }^{5}$ Para Hernández (1999, p. 85), por ejemplo, el elemento económico de la globalización es sustancial, tanto que, incluso, llega a negar el término, eligiendo, a cambio, el de "tercera revolución industrial".
} 


\section{LA SOBERANÍA JURÍDICA COMO UNA REALIDAD INTRINSECA Y PERMANENTE DEL ESTADO}

Como se ha señalado anteriormente, la globalización, en su fase actual, produjo un "acortamiento de las distancias" y una mayor "flexibilización" de las rígidas fronteras territoriales que, por muchos siglos, habían servido solamente para delimitar la exclusividad política y la plena autonomía sobre un conjunto de aspectos relacionados con la gestión, la defensa y la conducción de la sociedad en un territorio determinado, elementos que, por cierto, configuran el ejercicio de la soberanía estatal.

No obstante, si por un lado es verdad que en el actual mundo globalizado los Estados deben lidiar con fuerzas que tienen al menos el mismo impacto que ellos en la vida cotidiana de sus ciudadanos, habiendo perdido su privilegiada posición de exclusividad en el escenario internacional al romper un protagonismo absoluto como actor internacional que se consolidó desde el siglo XVIII hasta la segunda mitad del siglo XX, como señala Hobsbawm (1007, p. 115), por otro, la polémica surgida en torno al debilitamiento de la soberanía estatal parece un tanto desmesurada.

Aunque no se pueda negar que la globalización haya provocado cambios en las esferas política y jurídica de los Estados, los mismos no han sido suficientemente relevantes para modificar la forma de ejercicio de su soberanía jurídica (FALK, 2002, p. 50). Por consiguiente, los factores y fuerzas que cuestionan al Estado todavía no han adquirido el impulso necesario como para desarraigarlo.

Lo que se puede sostener es que la globalización permitió una cierta relativización de la soberanía. En esa perspectiva, como subraya Pacheco (2005, p. 146), lo que el Estado hace, en verdad, es adaptarse a nuevos contextos, aunque sacrifique parte de sus competencias, de sus funciones e, incluso, pueda llegar a abandonar algunas de las parcelas tradicionales de la soberanía, pero hace todo esto con la clara intención de sobrevivir o, asimismo, ganar nuevos poderes, facultades o prerrogativas.

Como observa Polin (1996, p. 12), jamás un Estado, por más poderoso que fuera, logró sustraerse integralmente a los condicionamientos de naturaleza jurídica o de orden fáctica, lo que es algo, inclusive, natural en la dinámica de las relaciones internacionales. De tal manera, una idea de soberanía sin límites, de hecho, nunca existió, y mucho menos tendrá lugar en los días actuales, especialmente en razón de las transformaciones históricas por las cuales los Estados han pasado.

Por consiguiente, la soberanía no sufrió una erosión equivalente a un juego de suma cero, sino que un desplazamiento, una transformación (HELD, MCGREW, 2003, p. 143-145), pero que no llega a poner en riesgo el pleno ejercicio del poder estatal en las esferas política y, principalmente, jurídica, internacionales y nacionales. De lo contrario, habría que buscar otro fundamento para la propia existencia del Estado. 
El Estado sigue manteniendo su lugar como el centro de legitimidad política, continuando sus funciones internas de satisfacción de las necesidades básicas de la gente mediante el ejercicio de la violencia legítima - para utilizar términos weberianos, - y a través de la prestación de los servicios esenciales de garantía y solidaridad, como señala Attinà (2001, p. 158), defendiendo y promoviendo con exclusividad el bien común a sus ciudadanos - al menos teóricamente -, pues sigue siendo el único detentor del ejercicio pleno de la soberanía en su territorio.

En este sentido, Canotilho (2002, p. 1276-1277) apunta que el padrón westfaliano de relacionamiento horizontal entre los Estados se mantiene casi que intacto, como modelo fundado en la soberanía, en la supremacía del orden jurídico interno, en la aplicación del Derecho Internacional en conformidad con los dictámenes de la legislación local y en la consideración de un pueblo territorialmente ubicado como fuente de legitimidad.

Como bien resume Sorensen (2010, p. 134), la soberanía sigue siendo el principio globalmente dominante de la organización política. Otro no es el entendimiento consolidado en el Informe 2005 de la ONU que afirma claramente que: "Los Estados soberanos son los componentes básicos e indispensables del sistema internacional"6.

En general, bajo la óptica del Derecho Internacional - y de acuerdo con la mayoría de los iusinternacionalistas ${ }^{7}$-, en el actual contexto globalizado el Estado sigue manteniendo la capacidad suficiente de decisión para garantizar la eficacia de sus decisiones dentro de las esferas de actuación interna y externa, justamente porque goza de la autonomía decisoria derivada de su soberanía. En otras palabras, la fuerza de la soberanía continúa justificándose en el detenimiento del monopolio del consentimiento por los Estados.

Ningún ente infra o supraestatal posee en la actualidad la condición constitucional de Estado, bien como ninguna institución o poder hace frente a su indiscutible legitimidad interna e internacional. Hasta mismo la conformación de la Unión Europea (UE) - el gran ejemplo cuando se trata del tema - no ha quitado el vital papel político, social y, especialmente, jurídico de sus Estados-miembros, pues, independientemente de las diferencias concernientes al poder económico y de una cierta cesión de competencias, todos siguen ostentando una soberanía de tipo formal ${ }^{8}$.

Por esa razón, se puede afirmar, incluso, que la sociedad internacional sigue rigiéndose esencialmente por una concepción predominantemente realista, o, más precisamente, neorrealista, pues la soberanía estatal permanece como expresión de la voluntad incondicionada de los Estados para que ocurra la cesión de algunas de sus competencias exclusivas.

\footnotetext{
${ }^{6}$ Véase: ONU. Informe del Secretario General de Naciones Unidas. Un concepto más amplio de la libertad: Desarrollo, seguridad y derechos humanos para todos, Doc. A/59/2005, par. 19.

${ }^{7}$ Véase, entre otros, Brotons (2007, p. 127).

${ }^{8}$ Asimismo, hay que señalar que tras la entrada en vigor del Tratado de Lisboa, las cesiones de soberanía están, claramente, refluyendo.
} vol.09, no. 04, Rio de Janeiro, 2016. pp. 2489-2506 
Eso porque es el voluntarismo que rige todo el mecanismo de funcionamiento interno del Estado, bien como su forma de actuación externa. En este punto hay que hacer notar que la convivencia con otros Estados igualmente soberanos continua siguiendo una dinámica de yuxtaposición.

\section{EL REGRESO DEL NACIONALISMO EN UN CONTEXTO DE INTERDEPENDENCIA ESTATAL}

Teniendo en cuenta todo lo anteriormente señalado, una consecuencia bastante preocupante de la actual fase de la globalización es la revivificación del nacionalismo. Ese fenómeno refleja que los muchos Estados pasaron a conducir a ejercer sus soberanías externas adoptando posturas políticas de matices neorrealistas. Según Berlin (1993, p. 438): "La ascensión del nacionalismo es hoy en día un fenómeno mundial, sin duda el factor más determinante en los Estados jóvenes y, en ciertos casos, entre las minorías de las viejas naciones".

Hay que subrayarse que el nacionalismo gana especial relieve en el análisis del impacto de la globalización en la sociedad internacional contemporánea porque, ab initio, esos dos fenómenos se contraponen, dificultando sobremanera las relaciones entre Estados, y conformando una situación bastante peculiar - para no decir paradojal -, pues al mismo tiempo que la globalización pugna por una creciente integración, el nacionalismo, al revés, quiere preservar al máximo la independencia del Estado y el pleno ejercicio de su soberanía.

Como ha señalado Vallespín (1998, p. 30), el nacionalismo, desde una perspectiva fragmentada que engloba identidades nacionales, religiosas, étnicas y culturales, viene constituyendo uno de los problemas fundamentales a los que la sociedad internacional actual debe enfrentarse hoy día, aunque, merece ser destacado, sea una teoría política tan antigua como la propia formación del Estado-moderno.

Como señala Hartmann (1983, p. 32), el fenómeno nacionalista siempre ha tenido y aún sigue teniendo gran peso en la vida internacional, incluso en los días de hoy, pues la propia conformación del orden internacional siempre ha girado alrededor de los Estados-nación, y sus cambios, así como las guerras acaecidas en su seno, generalmente se han debido a reivindicaciones de tipo nacionalista o a guerras de liberación nacional, como arguye Calera (2000, p. 84).

El nacionalismo es esencialmente un principio político que sostiene que debe haber congruencia entre la unidad nacional y la política. De acuerdo con Gellner (2008, p. 67):

[...] el nacionalismo es una teoría de legitimidad política que prescribe que los límites étnicos no deben saltar por encima de los políticos, y especialmente [...] que dentro de un Estado dado, no deben diferenciar a los detentadores del poder del resto. [...] Como ideario, puede apoyarse en varios buenos argumentos tales como conveniencia de salvaguardar la diversidad de culturas, así como la de un sistema político internacional pluralista y la de una disminución de las tensiones internas de los estados. [...] a menudo el nacionalismo no ha sido en realidad ni tan afablemente razonable ni tan racionalmente simétrico. 
Como no cabe en este análisis una profundización en el concepto y los orígenes del nacionalismo ${ }^{9}$, resta puntuarlo como una consecuencia grave de la actual etapa en que se encuentra la globalización, y señalar su reflejo inmediato en la forma como los Estados ejercen sus soberanías en el ámbito internacional.

Hay que tener presente que tras desmoronarse el orden bipolar que regía las relaciones internacionales en la segunda mitad del siglo XX, una nueva oleada nacionalista se produjo, conformándose dos tendencias contradictorias que han provocado una dinámica de choque: un nacionalismo favorable al statu quo y otro que deseaba acabar con él (SIMPSON, 1996, p. 56).

Entre las diversas causas que incentivan la reavivación de la llama nacionalista, la globalización aparece como la principal, una vez que ha permitido que las grandes naciones que se hayan visto favorecidas por sus consecuencias - principalmente desde un punto de vista económico - pudieran desarrollar una política de grandeza nacional, orientada y legitimada por un fuerte sentimiento de identidad y orgullo, conducta que tiende a fortalecer al Estado que la ejerce, a la vez que busca debilitar a los demás. Hay que destacar que la globalización, al aproximar a los Estados, igualmente acabó por provocar respuestas identitarias en amplias zonas del planeta ${ }^{10}$. Así que se puede afirmar que el pulso nacionalista sigue latiendo en el ámbito de las relaciones internacionales, a pesar de la mayor integración de la sociedad internacional - al menos desde un punto de vista económico. El nacionalismo sigue alimentando diferentes reivindicaciones en distintos países, lo que se ve reflejado en la forma de ejercicio de sus soberanías.

Lo preocupante de la cuestión es que al fundamentar el sistema internacional en una globalización que une y fragmenta al mismo tiempo, abriéndose espacio para que el nacionalismo fomente la autarquía política, se está rescatando, al final, la idea de soberanía acuñada en la Edad Moderna.

En definitiva, la realidad en la cual se encuentra en esos momentos la sociedad internacional ha favorecido la aparición y la consolidación de nuevos actores y de nuevas formas de relación, realzando el universalismo y la heterogeneidad de un sistema de yuxtaposición de Estados que conviven, de un lado, con la necesidad de una mayor cooperación y, de otro, con factores típicos de una sociedad institucionalizada.

\section{CONCLUSIÓN}

La cuestión que se quiso plantear es si la actual fase en que se encuentra la globalización ha servido, de alguna manera, para que los Estados se impusieran a sí mismos y a los demás, límites al ejercicio de la soberanía en el orden internacional. Con base en lo anteriormente establecido, parece ser que la respuesta sea negativa.

\footnotetext{
9 Sobre el concepto y los orígenes del nacionalismo, véanse, entre otros, Berlin (1993); Guerrero (2008); Kymlicka (2003); Pfaff (1994); y Smith (1997).

${ }^{10}$ En el continente europeo, por ejemplo, se puede citar la situación de la URSS, el último imperio multinacional, producto de una historia de opresión, inmovilismo y estancamiento de difícil parangón. Sobre el tema, véanse Arias (2001) y D'Encausse (2001). vol.09, no. 04, Rio de Janeiro, 2016. pp. 2489-2506 2500
} 
A pesar del mayor acercamiento y vigilancia recíprocos, los Estados siguen utilizándose de sus soberanías como escudos cuando no les convenga o, simplemente, cuando no quieran respetar la normativa de derecho internacional, aun cuando hayan sido reconocida por ellos mismos en el ámbito internacional.

Aunque autores como Faria (1990, p. 63-64) defiendan que la globalización generó una necesidad de normalización que puso en jaque el equilibrio monístico entre espacio territorial y espacio jurídico subyacente a las concepciones liberales de derecho, la soberanía sigue siendo el postulado fundamental del Estado y su ejercicio permanece condicionado a su exclusiva voluntad.

Lo que sí es plausible argumentar es que exista una cierta flexibilización en su ejercicio por los Estados cuando les convenga, hay que subrayar -, pero sería un tanto ingenuo hablar de una modificación en la estructura de un concepto jurídico tan arraigado, o incluso - como defienden los más radicales - de su eliminación, porque todo y cualquier posicionamiento a ser tomado por el Estado en la esfera jurídica internacional pasa por su consentimiento expreso, aunque haya presiones de orden político, o mismo económico, que de alguna manera puedan influir en sus decisiones.

Desde el punto de vista del derecho internacional, la soberanía sigue siendo el postulado fundamental en lo que concierne a la existencia misma de los Estados, estando regulada por dos principios mundialmente reconocidos: igualdad de los Estados, y no intervención (VELASCO, 2013, p. 282-283).

Esos dos principios enuncian formal y jurídicamente una condición de conservación de los Estados, ofreciendo a los más vulnerables, desde las ópticas política y económica, un estatus legal de protección que debe ser garantizado por la propia sociedad internacional, por medio, incluso, de la ONU o, más específicamente, por el Consejo de Seguridad.

La aceptación de esos principios garantiza en el ámbito de las relaciones internacionales, al menos jurídicamente, la supervivencia frente a Estados económica y políticamente más fuertes. Por otro lado, también es verdad que muchas veces los poderes políticos y económicos acaban influyendo en la propia elaboración de la normativa internacional.

En este orden de ideas, cabe destacar el tono crítico de Pastor Ridruejo (2006, p. 289) cuando afirma que el principio fundamental de la no intervención en los asuntos internos que son de jurisdicción exclusiva de otros Estados es uno de los principios que más y mejor se presentan a divergentes apreciaciones políticas e, incluso, a manipulaciones, por parte, sobre todo, de las grandes potencias y de las superpotencias. En cualquier caso, el principio de la no intervención está presente en diversos instrumentos internacionales que cristalizaron la obligación de los Estados de respeto mutuo a la soberanía.

Ahora bien, aunque se puedan vislumbrar cambios en la postura política de los Estados en la actual fase de la globalización - generalmente provocados por intereses económicos - la autonomía estatal sigue intacta en 
términos decisorios, y esos principios siguen sirviendo, incluso, para justificar posturas estatales disonantes de lo que se esperaría en términos de cumplimiento de los derechos humanos.

Conservando las características esenciales del modelo westfaliano, los Estados siguen apegados a un tipo de soberanía que gravita muy cerca de la concepción absoluta del término, abogando a favor de la independencia y la igualdad, factores fundamentales en una sociedad de yuxtaposición.

Son Estados que se comportan como los Estados están habituados a hacerlo, es decir, siguiendo los principios maquiavélicos y la razón de Estado, tal y como subraya Cooper $(1997,2005)$. En consecuencia, sus actos se dirigen de forma prioritaria a la satisfacción de los intereses nacionales propios.

En este sentido, como señala Sorensen (1999, p. 177-178), los Estados ejecutan en ámbito externo una especie de "juego de la soberanía westfaliano", o sea, un juego basado en la auto tutela, la no intervención y la reciprocidad.

No obstante que la democracia y los derechos humanos hayan pasado a formar parte contemporáneamente de los parámetros rectores de la sociedad internacional - al menos en Occidente -, muchos de los criterios realistas no desaparecieron en su forma de actuación y ese Estado dicho "globalizado" sigue conservando varios de los criterios soberanistas tradicionales.

Como afirma Kagan (2003, p. 10), los Estados no han renunciado a la crudeza de la geopolítica, y hasta mismo los Estados europeos, que tanto han sufrido con las dos Grandes Guerras mundiales, tampoco viven en un paraíso post-histórico de paz.

Tal vez se pueda afirmar que la problemática de la cuestión gire en torno a los diferentes usos que los Estados hacen de sus soberanías, siempre con base a los principios de independencia e igualdad consagrados en el artículo 2.1 de la Carta de la ONU, lo que parece demostrar que la soberanía, universal y homogénea en lo formal, se aplica y utiliza de manera bastante particularizada, de acuerdo con los intereses nacionales.

Por lo que se refiere específicamente a la globalización, como un fenómeno progresivo y continuo que es, hay que señalar que, de hecho, promovió un impacto significativo en la forma como la soberanía puede ser ejercida por los Estados, acentuando la tendencia de incorporación de actores no-gubernamentales (organizaciones internacionales, empresas, movimientos sociales y políticos transnacionales, etc.) a las relaciones internacionales, y provocando una reestructuración de la agenda política internacional, de manera que la estructura monocéntrica de poder de los Estados nacionales empezó a ser sustituida por un reparto de poder policéntrico.

No obstante, a pesar de las modificaciones apuntadas, en la fase en que se encuentra, aún no se puede afirmar que los factores y fuerzas que pasaron a cuestionar al Estado hayan adquirido el impulso necesario como para desenraizarla, o alterar su conceptuación política y jurídica. 
Al hilo de lo expuesto, lo que es posible sostener es que la evolución de las relaciones internacionales entre Estados, incrementada por la globalización, abrió camino para una nueva perspectiva de ejercicio de la soberanía jurídica basada en la flexibilización, con el objetivo de adaptarse a nuevos contextos, sacrificando parte de sus competencias y de sus funciones, pero con la clara intención de supervivencia.

En cualquier caso, el Estado sigue manteniendo su lugar como el centro de legitimidad política, correspondiéndole, con exclusividad el monopolio del uso de la fuerza en su territorio.

En definitiva, la globalización no afectó la soberanía jurídica en su esencia, pues, como se ha señalado, lo que se viene vislumbrando actualmente es un regreso a la adopción del patrón westfaliano de relacionamiento horizontal entre los Estados, típico del Realismo clásico. Eso porque los Estados siguen manteniendo capacidad suficiente de decisión para garantizar la eficacia de sus decisiones dentro de las esferas de actuación interna y externa, con base en los principios de la igualdad entre Estados y de la no intervención, permitiéndoles gozar del pleno ejercicio de sus soberanías, gracias a su autonomía decisoria en ella legitimada.

\title{
THE DIMENSION OF LEGAL SOVEREIGNTY AT THE CURRENT INTERNATIONAL GLOBALIZED SOCIETY
}

\begin{abstract}
This article aims to perceive and assess the legal scope of sovereignty from the perspective of its international projection, with the objective of finding that, despite the changes introduced by the globalization, especially at its current phase, in some measure, changed the form its exercise to match integration needs demanded by a new social, economic and political context, it is not possible to assert that factors and forces which came to question the role of the States in international society have acquired the necessary impetus to uproot or alter its legal status as an intrinsic element to the existence of the State. The methodology used in this research was descriptive and analytical, based on literature to construct its theoretical foundation.
\end{abstract}

Keywords: State; Globalization; Nationalism; Sovereignty; International society.

\section{REFERENCIAS}

AGUILERA DE PRAT, C. R. y VILANOVA, Pere. Temas de Ciencia Política. Barcelona: PPU, 1987.

ARIAS, Carlos Taibo. La explosión soviética. Madrid: Espasa, 2001.

ARENAL, Celestino del. "La nueva sociedad mundial y las nuevas realidades internacionales: un reto para la teoría y para la política" In VV. AA. Cursos de Derecho Internacional y Relaciones Internacionales de Vitoria Gasteiz. Bilbao: Universidad del País Vasco, 2001, p. 17-85.

"El nuevo escenario mundial y la teoría de las relaciones internacionales". In VV. AA. Hacia un nuevo 
orden internacional y europeo: homenaje al profesor M. Díez de Velasco. Madrid: Tecnos, 1993, p. 79-99.

ATTINÀ, Fulvio. El sistema político global: introducción a las relaciones internacionales. Barcelona, Buenos Aires, México: Paidós, 2001.

BARBÉ, Esther. Relaciones internacionales. 3. ed. Madrid: Tecnos, 2007.

BERLIN, Isaíah. "El retorno del bastón, sobre la ascensión del nacionalismo". In DELANNOI, Gil, TAGUIEFF, Pierre-André (comp.). Teorías del nacionalismo. Barcelona, Buenos Aires, México: Paidós, 1993, p. 425-449.

BIERSTEKER, Thomas J., WEBER, Cynthia. State Sovereignty as Social Construct. New York: Cambridge University Press, 1996.

BODINO, Juan. Los seis libros de la República. 3. ed. Madrid: Tecnos, 1997.

BROTONS, Antonio R. et al. Derecho Internacional. Valencia: Tirant lo Blanch, 2007.

CALERA, Nicolás López. "Nacionalismo y derechos humanos". In VV. AA. Los derechos: entre la ética, el poder y el derecho. Madrid: Dykinson, 2000, p. 83-88.

CANOTILHO, José Joaquim Gomes. Direito Constitucional e teoria da constituição. 6. ed. Coimbra: Almedina, 2002.

COOPER, Robert. "Is There a New World Order?" In MULGAN, Geoff (ed.). Life After Politics: New Thinking for the 21 Century. Londres: Fontana, 1997, p. 312-324.

D'ENCAUSSE, Hélène Carrèré. Rusia inacabada: las claves de la caída de un sistema político y el resurgir de un nuevo país. Barcelona: Salvat, 2001.

DALLARI, Dalmo de Abreu. Teoria geral do Estado. 30. ed. São Paulo: Saraiva, 2011.

DUVERGER, Maurice. Instituciones políticas y de derecho constitucional. 5. ed. Barcelona: Ariel, 1970.

FALK, Richard. La globalización depredadora: una crítica. Madrid: Siglo XXI, 2002.

FARIA, José Eduardo. "O futuro dos direitos humanos após a globalização econômica". In AMARAL JR,, Alberto do, PERRONE-MOISÉS, Cláudia (Orgs). O Cinqüentenário da Declaração Universal dos Direitos do Homem. São Paulo: Editora da Universidade de São Paulo, 1999, p. 55-73.

GELLNER, Ernest. Naciones y nacionalismo. 2. ed. Madrid: Alianza Universidad, 2008.

GIDDENS, Anthony. As conseqüências da modernidade. São Paulo: UNESP, 1991.

GUERRERO, Andrés de B. Escritos sobre nacionalismo. Madrid: Biblioteca Nueva, 2008.

HARTMANN, Frederick. The Relations of Nations. 6. ed. New York/London: MacMillan Publishers, 1983. 
HELD, David. Democracia y el orden global: del estado moderno al gobierno cosmopolita. Barcelona: Paidós, 1997.

MCGREW, Anthony. Globalización/Antiglobalización. Sobre la reconstrucción del orden mundial. Barcelona: Paidós, 2003.

HELLER, Hermann. La soberanía. México, D.F.: UNAM, 1995.

HERNÁNDEZ, Juan Ramón C. "Estado y Derecho ante la mundialización: aspectos y problemáticas generales". In HERNÁNDEZ, Juan Ramón C. (coord.). Transformaciones del Derecho en la mundialización. Madrid: Consejo General del Poder Judicial, 1999, p. 85-121.

HOBSBAWM, Eric. Guerra y paz en el siglo XXI. Barcelona: Crítica, 2007.

Historia del siglo XX: 1914-1991. Barcelona: Crítica, 1995.

KAGAN, Robert. El retorno de la historia y el fin de los sueños. Madrid: Taurus, 2008.

KAPLAN, Morton, KATZENBACH, Nicholas B. Fundamentos políticos do direito internacional. Rio de Janeiro: Zahar, 1964.

KEOHANE, Robert O. Power and Governance in a Partially Globalized World. London/New York: Routledge, 2002.

KYMLICKA, Will. La política vernácula: Nacionalismo, multiculturalismo y ciudadanía. Barcelona, Buenos Aires, México: Paidós Estado y Sociedad, 2003.

MENÉNDEZ, Fernando M. M. Derecho Internacional Público: parte general. 4. ed. Madrid: Trotta, 2005.

PACHECO, Pedro M. "Estado y globalización: ¿Crisis o redefinición del espacio político estatal?" In CANCIO MELIÁ, Manuel (coord.). Anuario de la Facultad de Derecho de la Universidad Autónoma de Madrid: Globalización y Derecho. 2005, núm. 09, p. 127-151.

PASTOR RIDRUEJO, José Antonio. Curso de Derecho Internacional Público y Organizaciones Internacionales. 17. ed. Madrid: Tecnos, 2013.

PAUPÉRIO, Artur Machado. Teoria democrática da soberania. 3. ed. Rio de Janeiro: Forense Universitária, 1997, vol. 2.

PFAFF, William. La ira de las naciones: la civilización y las furias del nacionalismo. Buenos Aires, México, Santiago de Chile: Editorial Andrés Bello, 1994.

POLIN, Raymond. "Le concept de souveraineté et ses conséquences internationales". In GRACO, Roland (Org.). Souveraineté de l'Etat et interventions internationales. Paris: Dalloz, 1996, p. 5-15.

REALE, Miguel. Teoria do direito e do estado. São Paulo: Saraiva, 2002.

ROSENAU,James. Turbulence in World Politics. Brighton: Harvester, 1990.

ROSENAU, James N. "Sovereignty in a Turbulent World". In LYONS, Gene M., MASTANDUNO, Michael (eds.). Beyond Westphalia: State Sovereignty and International Intervention. Baltimore: The John Hopkins vol.09, nº. 04, Rio de Janeiro, 2016. pp. 2489-2506 2505 
University Press, 1995, p. 101-227.

SALCEDO, Juan Antonio C. Soberanía del Estado y Derecho Internacional. 2. ed. Madrid: Tecnos, 1976.

SALVETTI NETTO, Pedro. Curso de Ciência Política: teoria do Estado. 2. ed. São Paulo: Tribuna da Justiça, 1977, vol. 1.

SIMPSON, Gerry J. "The Diffusion of Sovereignty: self-determinations in the Post-Colonial Age". In SELLERS, Mortimer (ed.). The New World Order: Sovereignty, Human Rights and Self-Determination of Peoples. Oxford, UK: Berg, 1996, p. 35-69.

SMITH, Anthony D. La identidad nacional. Madrid: Trama Editorial, 1997.

SORENSEN, Georg. "Sovereignty: change and continuity in a fundamental institution". In JACKSON, Robert (ed.). Sovereignty at the Millenium. Reino Unido: Blackwell Publishers, 1999, p. 168-182.

La transformación del Estado más allá del mito del repliegue. Valencia: Tirant lo Blanch, 2010.

STIGLITZ, Joseph E. El malestar en la globalización. México: Taurus Pensamiento, 2003.

VALLESPÍN, Fernando. "Cosmopolitismo político y sociedad multicultural". In VALENCIA SÁIZ, Angel (coord.). Participación y representación políticas en las sociedades multiculturales. Málaga: Universidad de Málaga/Debates, 1998, p. 29-46.

VAN STADEN, Alfred, VOLLAARD, Hans. "The Erosion of State Sovereignty: towards a post-territorial world?" In KREIJEN, Gerard (ed.). State, Sovereignty, and International Governance. Nueva York: Oxford University Press, 2004, p. 165-184.

VELASCO, Manuel Díez de. Instituciones de Derecho Internacional Público. 18. ed. Madrid: Tecnos, 2013.

WENDT, Alexander. "Anarchy is what states make of it: the social construction of power politics". International Organization. 1992, vol. 46, núm. 2, p. 391-425.

Trabalho enviado em 05 de março de 2016.

Aceito em 02 de junho de 2016. 